\title{
Interactional Markers in English Medical Research Articles Written by Iranian and Native Authors: A Contrastive Metadiscourse Analysis of Method Section
}

\author{
Fariba Ghadyani (Corresponding Author) \\ English Language Department, Sheikh-e-Bahaee University, Isfahan, Iran \\ E-mail: ghadyani.fa@gmail.com \\ Mohammad Hassan Tahririan \\ English Language Department, Sheikh-e-Bahaee University, Isfahan, Iran \\ E-mail: tahririan@shbu.ac.ir
}

Doi:10.7575/aiac.alls.v.5n.4p.137

Received: $11 / 06 / 2014$

URL: http://dx.doi.org/10.7575/aiac.alls.v.5n.4p.137

Accepted: 18/07/2014

\begin{abstract}
To determine the issue of whether there were any significant differences between the groups including Iran ISI, Iran non- ISI, and native authors in binary comparisons as for employing interactional markers, the present study was conducted. To collect the data, 90 'method sections' of English medical research articles within Iranian ISI, Iranian nonISI, and native ISI journals written by Iranian and native authors published between 2005 and 2010, were examined. As the model of analysis, Hyland's (2005) taxonomy of metadiscourse markers was used. After performing quantitative and qualitative analyses of the interactional markers, Chi- Square tests were run. The results of the study at $\mathrm{p}=0.05 \mathrm{revealed}$ significant differences in binary comparisons made up of native / Iran ISI, native / Iran non- ISI, and Iran ISI/ Iran nonISI as for employing self-mentions. The findings also demonstrated a significant difference between Native and Iran ISI groups for using boosters. These differences may be influenced by the writers' mother tongue, culture and also by their lack or limited awareness of the rhetorical conventions of English medical academic research writing which are needed to be taken into consideration.
\end{abstract}

Keywords: metadiscourse analysis, interactional marker, method section, medical research article, Iranian, ISI journal

\section{Introduction}

Due to increasing importance of English language as the dominant international language of research (Swales, 2004), it is expected that speakers of other languages, especially those who are engaged in ESP and EAP communicate effectively in a global context. Furthermore, writing persuasive scientific academic texts, per se, in second or foreign language writing for being accepted, and published in particularly, internationally indexed or prestigious journals is a fundamental means of securing scientific change (Livnat, 2012). Medicine is no exception to this rule as medical research articles are the genre, the mastery of which is very important to the professional success of researchers. According to Swales (1990), the researchers' career is almost entirely dependent on their ability to write successful academic articles, publish them in the reputed journals, and ultimately cause others to cite them. In fact as he argues (1990), writers of medical research articles within their discourse community need to know how to write in accordance with the social aims, the form, the structure and the formulations that reflect the structure of the specific disciplinary community, that is, its norms, and conventions .

Swales introduced a prototypical structure and various formal features as signaling moves (Lewin, Fine, \& Young, 2001; Samraj, 2002a;Samraj,2002b) in English- written article introductions in a range of disciplines in his seminal work (1990)as the three-part CARS (Creating a Research Space) model. His work were followed by a group of researchers who have sought to describe the conventional rhetorical structure of the articles within various parts of them through move analysis identifying distinct rhetorical units that perform coherent communicative functions(Swales, 2004).

Different types of genres in academic written English including textbooks, various sections of research articlesparticularly- introductions-, abstracts, theses and dissertations, acknowledgements and their titles were subsequently analyzed in various EAP fields of study. Much of these researches have focused on organizational patterns of RAs. Brett (1994) studied result sections in sociology RAs; Berkenkotter \& Huckin( 1995) examined discussion sections across a wide range of sciences; Hopkins \& Dudley Evans(1988) studied articles and dissertations; Peacock( 2002)scrutinized seven disciplines within all the four sections ; Kanoksilapatham (2005) studied the schematic structure of literature reviews in biochemistry ; Kwan( 2005)examined doctoral theses of Applied Linguistics; Thompson (1994) studied academic spoken discourse, on areas of applied linguistics, engineering, and medicine, and 
finally, titles of review papers and research papers; and Soler (2007) examined writing titles in disciplines of social sciences and biology.

The existence of extensive portion of recent works of ESP genre analysis has proven a growing interest in interpersonal dimensions of academic writing, for example, imperatives (Hyland, 2002; Swales et al,1998), personal pronouns (Hyland, 2001a; Kuo, 1999), hedging and boosting (Hyland, 1998b; Myers, 1989; Salager-Meyer, 1994), theme(Gosden, 1993), and citation practices (Hyland, 1999a; Thompson, 2000).

The accomplished studies regarding metadiscourse include the works done by researchers in Scandinavia (Finland and Sweden), the rest of Europe (Italy, Slovenia, and Spain), Asia (Hong Kong and Iran), Australia and the US (Adel, 2010). Avon Crismore, as a pioneer, started publishing on metadiscourse as early as the late 1980s. At the other end of the spectrum, recent researches were carried out by master's and Ph.D. students (Crismore \& Abdollehzadeh, 2010). Some studies have concentrated on the role of metadiscourse as for pedagogical purposes. These include the effect of students' awareness of metadiscourse on their writing skill (Cheng \& Steffensen, 1996), reading (Camiciottoli, 2003; Jalilifar \& Alipour 2007; Parvaresh \& Nemati, 2008), and listening comprehension (Pérez \& Macià, 2002; Hashemi et al., 2012), and speaking abilities. In medical disciplinary, until the publication of Nwogu's article in 1997, only a few studies have attempted to investigate the organization of information in scientific research reports. Contrastive studies of the rhetorical microstructural features of native and non- native speakers of English comprise a valuable literature with regard to metadiscourse analysis.

Literature in the area of contrastive genre analysis highlights that medical RAs have not been studied for employing metadiscourse features. Furthermore, to the best knowledge of the writer 'method section' of RAs in general and of medical RAs in particular, has not been paid attention in this regard. However, as Swales (2004) argues, it should not lead us to think that writing 'method section' is relatively uncomplicated. Furthermore, 'method section' has been largely ignored while methods and procedures determine the ways in which other sections are constructed, and they give corporeal substance to the ideas, and produce certain kinds of data in certain amounts to make certain claims possible (Swales, 2010). Moreover, editors of major journals often operate 'methodological screens', and reject out of hand submissions that do not meet their methodological expectations (Swales, 2010). On the other hand, metadiscourse as a rhetoric device could contribute to achieving an efficient writer- reader communication and also as Hyland (2004b) argues, it displays researchers' competence as disciplinary insiders to establish relationships between their ideas and the people, Eventually, due to the mentioned grounds, the present study was conducted to contribute to elicit probable distinctive features of interactional markers having been employed across medical articles by Iranian authors of Iranian ISI journals written in English (as a criterion of the high degree of prestige and credibility within indexed journals ) and by Iranian authors of Iranian non-ISI journals written in English in comparison with the English ISI medical RAs written by native authors in order to exploit the outcomes for pedagogical purposes and to shed light on planning appropriate materials for explicit teaching of writing medical RAs.

\subsection{Theoretical Background}

Three original influential theories comprise the theoretical basis of the present study: Contrastive Rhetoric Hypothesis (CR), Genre Theory, and Metadiscourse Theory.

According to Valero-Garcés (1996) rhetoric refers to "the strategies the writer uses to convince readers of his/her claim and to increase credibility of his/her researcher." The study of contrastive rhetoric was introduced in 1960s by Robert Kaplan who examined six hundred L2 student essays written by non- native English- speaking students and he explored that there is a link between cultural thought patterns and paragraph structures (language) in the essays. He claims that "the foreign- student paper is out of focus because the foreign student is employing rhetoric and a sequence of thought which violates the expectation of the native reader "(Kaplan, 1966). According to more clarifications that Kaplan (2000) has made on the purpose of CR, the field assumes that languages differ not only in phonological, morphological, and grammatical features, but in the kinds of genres available to their speakers for organizing discourse and in the rhetorical (and syntactic) features that co-occur with those genres. Kaplan himself has modified his earlier position and suggested, for example, that rhetorical differences do not necessarily reflect different patterns of thinking. Instead, differences may reflect different writing conventions that have been learned rather than acquired (Conner, 2004). Conner (2002) states that:

"In contrastive rhetoric, they have certainly not interpreted all differences in L2 writing as stemming from the L1 or interference from the national culture. Instead, they have explained such differences in written communication as often stemming from multiple sources, including L1, national culture, L1 educational background, disciplinary culture, genre characteristics, and mismatched expectations between readers and writers. Although CR largely was restricted throughout much of its first 30 years to fairly rigid formstudent essay writing- the field today contributes to knowledge about preferred patterns of writing in many ESP situations."

Three traditions of genre analysis are usually distinguished by Hyon (1996), which can be seen as complementary, rather than competing approaches: English for Specific Purposes (ESP) genre analysis, New Rhetoric studies, and a distinctive Australian approach that draws on systemic functional linguistics extensively (SFL).

Aristotle defines rhetoric as the faculty of observing in any given case, the available means of persuasion (Honeycutt, 2000). Aristotelian definition of rhetoric has extremely influenced modern understanding of the term through its emphasis on 'persuasion'. The New Rhetoric Approach influenced by post-structuralism, rhetoric and first-language 
composition, that is, it studies genre as a motivated and functional relationship between text type and rhetorical situation (Coe, 2002).

SFL provides a theoretical approach to genre within a framework for understanding the relationship of form and context. According to Eggins (1994) Systemic functional linguistics is concerned with how people use language and how language is structured for use. Further, systemic functional linguistics views meaning as social as that social meaning impacts on linguistic forms. In other words, the role of form is to serve a social function.

ESP genre analysis has its origins in Swales' $(1981,1990)$ studies of discourse structure and linguistic features of scientific research articles. His work was followed by a group of researchers who have sought to describe the conventional rhetorical structure of the articles within various parts of them through move analysis identifying distinct rhetorical units that perform coherent communicative functions (Swales, 2004).

ESP and Australian genre scholars have shown more tendency than the New Rhetoric Studies to teaching different genres explicitly and have thus been more interested in construction of models and materials for teaching genres (Hyon, 1996).

The original assumption underlying metadiscourse stems from Malinowski (1927) who argues that human language is capable of not only reflecting thought but also creating bonds of union between interlocutors as well, while he dubs the latter function of language "phatic communion"(Mao, 1996). The term metadiscourse was coined for the first time by Zellig Harris in 1959 and he demonstrated the ways in which the writer or the speaker "conduces" the receiver's perception of a text through the use of language (Cavalieri, 2011).

Metadiscourse was neglected during the 1960s and 1970s and later in the 1980s; it was adopted in discourse studies by some scholars as Williams (1981); Vande Kopple (1985); and Crismore (1989) who were interested in writing instructions. Moreover, by the early 1990s, linguists reacted against strong emphasis on propositional meaning in text analysis and this movement led to a range of new perspectives on text, among which studies of metadiscourse gained prominence (Hyland, 2002).

Crismore (1984) believes that the aim of metadiscourse is to "direct rather than inform the readers"(p. 280). Vande Kopple (1985) defines metadiscourse as "discourse that people use not to expand referential material, but to help the readers connect, organize, interpret, evaluate, and develop attitudes towards that material"(p:84). Similarly, Hyland (2005) believes that metadiscourse embodies the idea that communication is more than just the exchange of information, goods or services, and involves the personalities, attitudes and assumptions of those who are communicating.

On the other hand as Adel and Mauranen (2010) argue, according to different definitions of metadiscourse, metadiscourse has been variously understood and this has led to the "fuzziness" which Hyland (2005), and others (e.g. Bondi 2005; Swales 1990) have found in the concept and it is this lack of clarity that Hyland (2005) seeks to overcome in his critique of earlier accounts of metadiscourse and while his proposed model has been built on previous work, is nevertheless able to offer a more coherent analytical approach.

According to Hyland (1999b) 'metadiscourse' is a crucial rhetorical device; moreover he (2005) analyzes the relation between genre, discourse community, and metadiscourse. The concept of discourse community in addition to the notion of genre conveys the idea that people generally use language to communicate with individuals that are members of the same social group (Hyland, 2005). He also maintains that the choice of the metadiscourse strategies linked to the shared knowledge of a particular discourse community and indeed to understand its pragmatic use, metadiscourse must be observed in the genres which give it meaning (Hyland, 2005). As Hyland (2005) states, the term refers to discoursal choices that writers use to signal their attitude to their subject matter and their readers and to influence how their readers receive their text.

A number of metadiscourse taxonomies have been proposed in literature some decades ago so as to classify metadiscourse markers according to their form, meaning, or function (Vande Kopple 1985, 2002; Barton \& Stygall, 2002; Crismore et al, 1993; Beauvais 1989; Hyland, 1998a, 2005; Dafouz, 2003). However, most of them with the exception of Beauvais (1989) generally organize the linguistic units under the functional headings of textual and interpersonal metadiscourse. Textual metadiscourse refers to the organization of discourse, while interpersonal metadiscourse reflects the writer's stance towards both the content in the text and the potential reader. Hyland (2000, 2005) has provided the probably most comprehensive framework for the study of metadiscourse. Dalton-Puffer, Nikula and Smit (2010) argue that Hyland (2005) as well as Hyland and Tse (2004) have put forth another interpersonal view on metadiscourse, claiming that all metadiscourse categories are essentially interpersonal since they need to take into account the readers' knowledge, textual experiences and processing needs. They have adopted Thompson's (2001) label of interactive (instead of textual) and interactional (instead of interpersonal) metadiscourse. Hyland (2005) classifies metadiscourse expressions into two macro-categories including interactive and interactional as interactive expressions are used to organize propositional information in ways that a projected target audience is likely to find coherent and convincing and the interactional dimension which concerns the ways writers conduct interaction by intruding and commenting on their message. It should be mentioned that these two macro-categories were previously referred to as textual and interpersonal by Halliday in the systemic functional grammar (Hyland, 2005). He (2005) employs ten subcategories which represent a broader distinction between interactive and interactional resources. Categories of the interactive type are concerned mainly with organizing discourse and its interpretation, whereas the interactional elements are concerned with creating a writer personality and involvement with the reader. 


\section{Material and Methods}

\subsection{The Corpus}

This study examined 90 'method sections' of English medical research articles, having the standard IMRD structure published in ISI and non-ISI journals. They comprised the three study groups: Native, Iran ISI, and Iran non-ISI groups. Each of them consisted of 30 articles selected respectively from ISI Native journals, ISI Iranian Journals, and Iranian non- ISI journals. It is imperative to mention that Nativeness was defined in terms of the context in which the articles are published in order to delimit and maintain the reliability of the study. Three groups of medical journals constituted the corpus of the study:

1-English medical journals published in English native speaking contexts selected from among a ranking list at (SCImago) at the website of SJR including the highest impact and prestigious journals because popularity and prestige were both taken into consideration.

2- Iranian ISI medical journals published in English selected from among a ranking list at (SCImago) under the title of Iranian journals indexed in international website of SJR.

3-Iranian non-ISI medical journals published in English selected from among the general list of Scientific Information Database (SID) Articles Published in Iran. These journals are mostly registered by other international indexing systems such as Iran Medex, Scopus, Index Medicus, Pub Med, Medline, etc.

To balance out the problem of peculiarities of writers' styles, these articles have been selected through stratified random sampling. Moreover, equal number of articles (i.e., 5 articles) has been selected from among the articles of each journal randomly, irrespective of the differences in frequency of annual publications among them.

\subsection{Process of Random Selection of the Corpus}

The choice of research articles was based on a number of criteria; the first criterion was, having experimental design in order to have homogeneous data because research articles in medicine mainly deal with experimental research. The second criterion was, having IMRD structure. Then, the research articles were all restricted to those published within 2005-2010 with the assumption that time influences the style of the writers. To increase the external validity of findings, the articles were selected irrespective of medical specialty, that is, they were of diversity in subject as possible. Random selection was carried out 18 times for the 18 types of the journals to select 5 articles from each journal by means of stattrek stratified random sampling at (http: //stattrek.com/Tables/Random. aspx).

\subsection{Instrumentation}

\subsubsection{Framework of the study}

Several metadiscourse models have been introduced since the inception of the concept of metadiscourse. All of the models, in one way or another, are recognitions of a belief that the use of language for communication is not just an attempt to transfer information and knowledge; rather it is also normally accompanied by cooperative efforts like organization, evaluations, feelings, engagement, etc.

These two macro-categories were previously referred to as textual and interpersonal, respectively by Halliday in the systemic functional grammar. The change of labels was put forward by Hyland who claims that all metadiscourse needs to be conceptualized as an interpersonal feature of communication 'in that it takes account of reader's knowledge, textual experiences, and processing needs (Hyland, 2010;; Hyland 2005 ; Hyland, and Tse, 2004).

\subsection{Procedure of the Study}

\subsubsection{Performing Pilot Test}

Performing pilot test at first stage demonstrated some significant differences as for the employed interactional markers between the mentioned study groups. Based on the feedback from the pilot test, the study was conducted completely using the Hyland's (2005) Model. The metadiscourse analysis of the articles was conducted through analyzing 'method sections' of all the medical articles to explore the frequency of the employed sub- types of interactional markers within them. Then, it was followed by qualitative stage.

\subsubsection{Quantitative Procedure}

A list of 91 potentially productive searched interactional items to express the sub-types of interactional resources (Appendix 1) was compiled based on previous research on metadiscourse features (e.g. Hyland, 2007; Vazquez \& Giner, 2009), and on a careful study of the corpus themselves for eliciting the most frequently occurring items in the articles being examined.

The research articles in PDF format were converted to text form by the Simpo PDF Convertor software. Then, the texts were converted to an electronic corpus of 81,562 numbers of words using MAXQDA text analysis software and searched for the frequency of the specific features.

\subsubsection{Qualitative Procedure}

The results of the quantitative stage in the research articles were examined in the context to ensure the multifunctionality nature of interactional markers in method sections to verify the validity of the results and a small sample was double-checked by a colleague working independently to verify the results to attain the reliability of the findings. 


\subsubsection{Performing normalization}

The frequencies of the interactional markers totally and individually as well as the total number of words were obtained. Since consistency of the length of the articles is a 'must' to make the results comparable, the obtained data was calculated in 10000 words.

\subsubsection{Intra-rater and Inter-rater Reliability}

To determine inter- rater reliability, method sections of 90 randomly selected articles were analyzed by the researcher. Then, a small sample of the same articles analyzed by a colleague of the researcher- an M.A. holder of TEFL- who received sufficient training in doing the task. The obtained value of Spearman's correlation coefficient (rho) between the two ratings $(r=0.81)$ was an estimate of the high inter- rater reliability of the judgments made by the researcher and the rater. Furthermore, the second analysis of the same sections of the same articles by the researcher was done at a two weeks interval. The calculated correlation between the two results by the researcher $(r=0.83)$ was an estimate of high intra- rater reliability of the judgments made by the researcher on two different times.

\subsection{Data Analysis}

Inasmuch as the research questions concerning the metadiscourse analysis of the present study dealt with sets of binary comparisons including Native /Iran ISI, Native/Iran non- ISI, and Iran ISI/ Iran non- ISI, sets of statistical tests were performed on the data, that is, chi-square tests were run between the pairs of frequency counts concerning single subtypes of interactional markers individually, in order to examine probable significant differences between them to test the hypotheses of the present study.

\subsubsection{Hypotheses of the study}

1- There is no significant difference in employed interactional markers between English medical ISI and English nonISI articles written by Iranian writers.

2-There is no significant difference in employed interactional markers between English medical ISI articles written by Iranian writers and those written by native speakers of English.

3- There is no significant difference in employed interactional markers between English medical non-ISI articles written by Iranian writers and English medical ISI articles written by native speakers of English.

\subsubsection{Research questions}

1-What are distinctive features of medical articles written by Iranian writers in ISI and non-ISI journals as for employing interactional markers.

2-What are distinctive features of medical ISI articles written by Iranian writers and those written by native speakers of English as for employing interactional markers.

\subsection{Variables of the Study}

\subsubsection{The Dependent Variables}

The frequency of each sub-type of interactional markers used in method section of English medical research articles written by Native, Iran ISI, and Iran non- ISI groups of authors.

\subsubsection{The Independent Variables}

The rhetorical aspect of using sub- types of interactional markers in native ISI, Iran ISI, and Iran non- ISI English medical research articles within the study groups.

\section{Results}

Totally 1,092 instances of interactional markers were exploited within the corpus of the study. The Native group has employed 680 instances of interactional markers. The Iran ISI and the Iran non- ISI groups have employed 225 and 187 instances of interactional markers respectively (Table 3.1). These findings are more clearly evident by a bar graph below (chart 3.1).

Table 3.1 Frequency rates of the five sub-types of interactional markers individually, and those of total interactional markers

\begin{tabular}{lcccc}
\hline & \multicolumn{3}{c}{ The Study Groups } & \\
\cline { 2 - 4 } $\begin{array}{l}\text { Sub-types } \\
\text { of }\end{array}$ & Native & Iran ISI & Iran Non- ISI & Total \\
$\begin{array}{l}\text { Interactional } \\
\text { Markers }\end{array}$ & & & \\
Self- mentions & & & & 295 \\
Engagement Markers & 243 & 36 & 16 & 16 \\
Attitude Markers & 16 & 0 & 0 & 26 \\
Boosters & 18 & 6 & 2 & 574 \\
Hedges & 296 & 146 & 132 & 181 \\
Total Interactional & 107 & 37 & 37 & 1092 \\
Markers & 680 & 225 & 187 & 81562 \\
Total Words & 46944 & 16230 & 18388 & \\
\hline
\end{tabular}




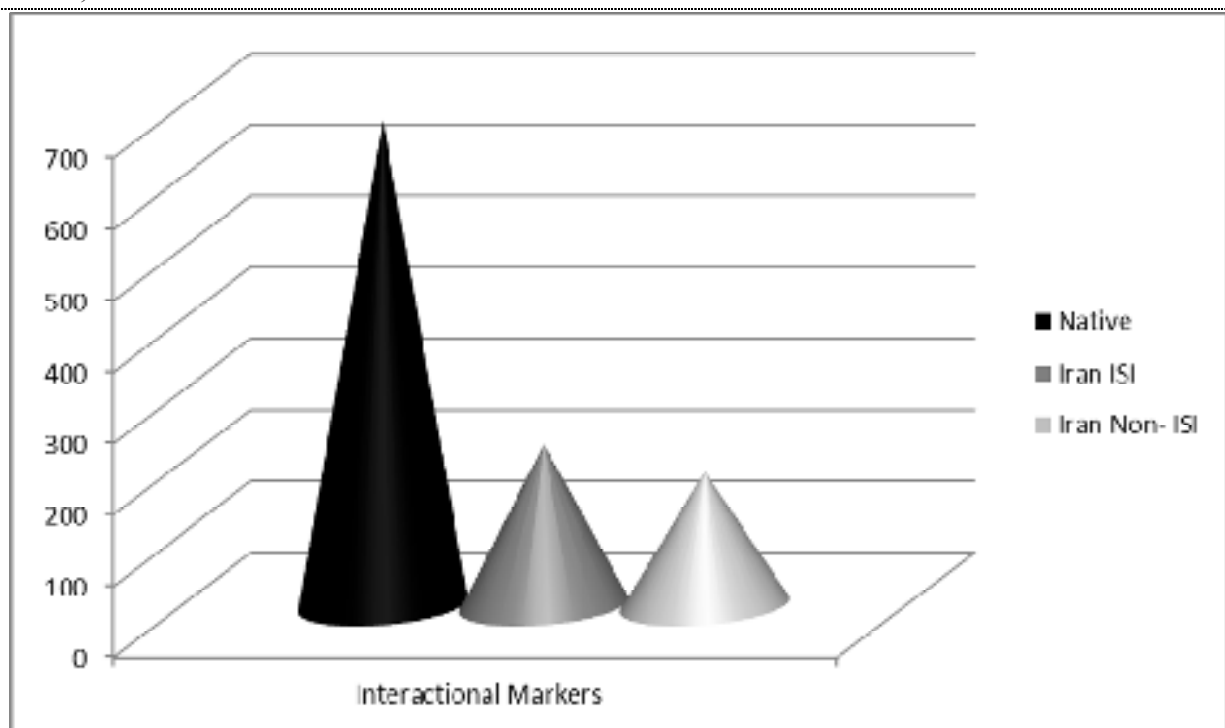

Chart 3.1 Bar graph representing total number of interactional markers across 'method section' of medical research articles used by the study groups

Statistically, the number of interactional markers, totally and individually were calculated per 10000 words (Normalization). The Native group employed 144.84 instances of interactional markers, totally. The Iran ISI group with a total number of 138.63 instances for interactional markers stood in the highest position; however, the Iran non- ISI group with 101.70 instances of total interactional markers ranked the lowest position among the three study groups (Table 3.2). This is depicted by a bar graph below (chart 3.2).

Table 3.2 Frequency rates of the 5 Sub-types of interactional markers individually as well as those of total interactional markers across 'method section' of medical research articles (per 10000 words)

\begin{tabular}{lccc}
\hline \multirow{2}{*}{$\begin{array}{l}\text { Sub-types } \\
\text { of Interactional } \\
\text { Markers }\end{array}$} & Native & Iran ISI & Iran Non- ISI \\
\cline { 2 - 3 } & & & \\
Self- Mentions & 51.76 & 22.18 & 8.70 \\
Engagement- & 3.41 & 0.00 & 0.00 \\
Markers & & & \\
& 3.83 & 3.70 & 1.09 \\
Attitude Markers & 63.05 & 89.96 & 71.79 \\
Boosters & 22.79 & 22.80 & 20.12 \\
Hedges & 144.84 & 138.63 & 101.70 \\
Total & & & \\
\hline
\end{tabular}

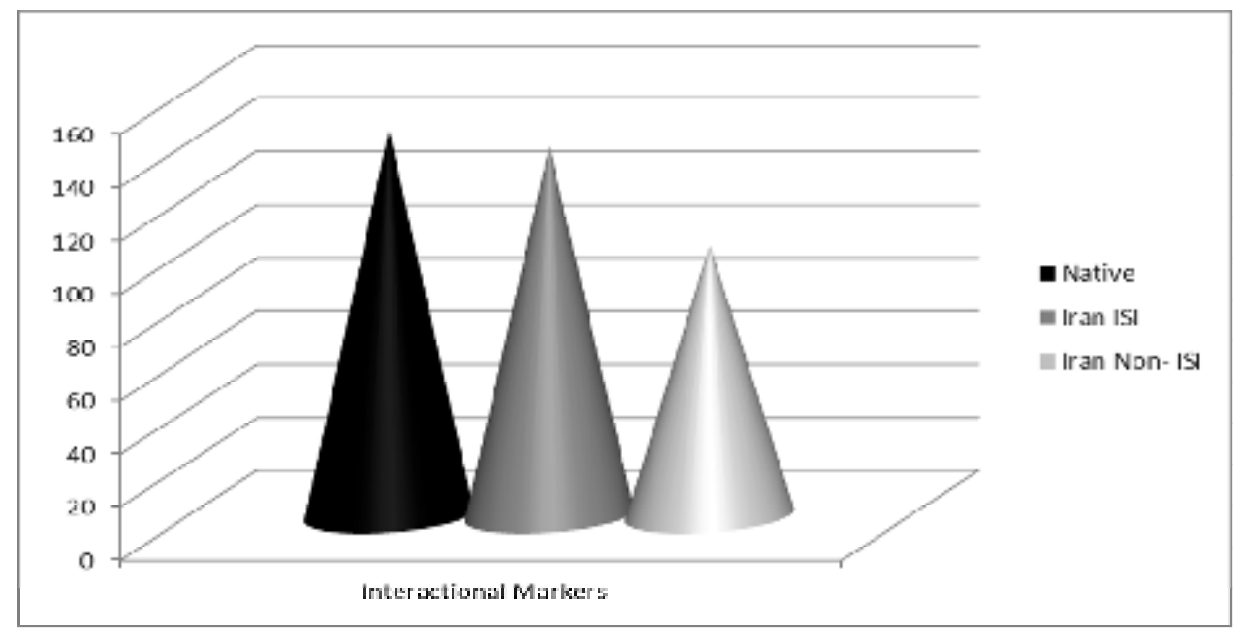

Chart 3.2 Bar Graph representing interactional markers across 'method section' of the medical research articles used by the study groups 
Frequency rates of the five sub- Types of interactional markers in percentage terms indicated that boosters comprised maximum percentage of them used in each study group, but engagement markers were of minimum percentage of interactional markers employed in each study group (Table 3.3). The findings are best depicted in chart 3.3 below.

Table 3.3 Frequency rates of the five sub-types of interactional markers across 'method section ' of medical research articles used by the study groups (In percentage terms)

\begin{tabular}{lccc}
\hline & \multicolumn{2}{c}{ The Study Groups } \\
\cline { 2 - 4 } $\begin{array}{l}\text { Sub-types } \\
\text { of Interactional } \\
\text { Markers }\end{array}$ & Native & Iran ISI & Iran non- ISI \\
Self -mentions & 35.73 & 16.00 & 8.56 \\
Engagement & 2.35 & 0.00 & 0.00 \\
Markers & & & \\
Attitude Markers & 2.65 & 2.67 & 1.07 \\
Boosters & 43.53 & 64.89 & 70.59 \\
Hedges & 15.74 & 16.44 & 19.79 \\
Total & 100.00 & 100.00 & 100.00 \\
\hline
\end{tabular}

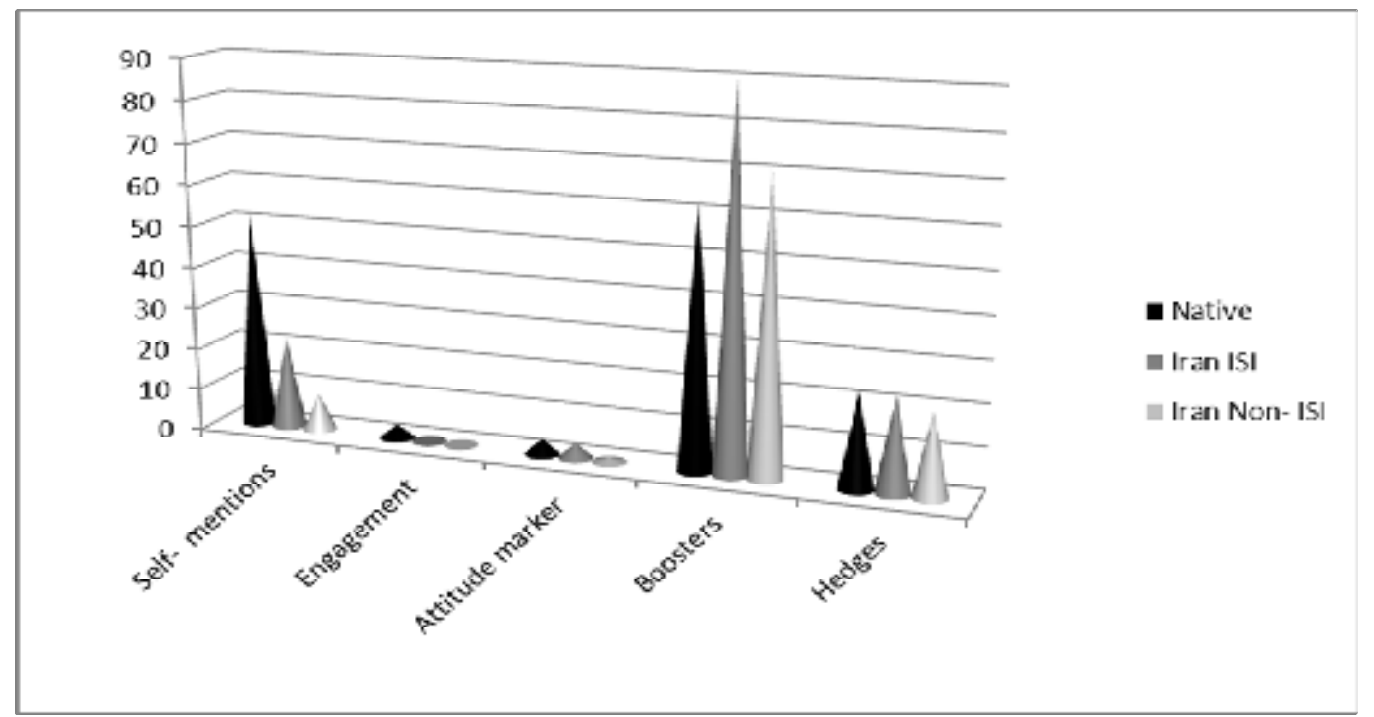

Chart 3.3 Bar graph representing the five subtypes of interactional markers individually across 'method section' of medical research articles used by the study groups

Chi- Square tests were run in order to examine probable significant differences between the Native group and the other study groups for employing interactional markers individually. The results showed that there were not any significant differences between the Native and the Iran ISI as well as Iran non-ISI group individually in this regard (Table 3.4). On the other hand, Chi- Square tests were run in order to examine probable significant differences between the Iran ISI group and the Iran non- ISI group. The findings indicated that there was not any significant difference between the Iran ISI and the Iran non- ISI, for using interactional markers (Table 3.4).

Table 3.4 Results of Chi- Square tests of the Native group, the Iran ISI and Iran non-ISI groups for using interactional markers across 'method section' of medical research articles

\begin{tabular}{lccc}
\hline & \multicolumn{2}{c}{ The Binary Comparisons } \\
\cline { 2 - 4 } & $\begin{array}{c}\text { Native } \\
\text { / Iran ISI }\end{array}$ & $\begin{array}{c}\text { Native } \\
\text { / Iran Non- ISI }\end{array}$ & $\begin{array}{c}\text { Iran ISI } \\
\text { / Iran Non- ISI }\end{array}$ \\
$\begin{array}{l}\text { Value of } \\
\text { Shi- }\end{array}$ & 0.14 & 7.55 & 5.68 \\
Square & 4 & 4 & 4 \\
DF & 0.05 & 0.05 & 0.05 \\
$\mathbf{P}$ & 283.48 & 246.55 & 240.33 \\
\hline
\end{tabular}


Chi Square tests were run to determine probable significant differences within the binary comparisons including the Native/Iran ISI, Native/Iran non- ISI, and Iran ISI/Iran non- ISI as for employing each sub-type of interactional markers (Table3.5).

Table 3.5 Results of Chi- Square tests of the study groups individually, for using each of the five subtypes of interactional markers across 'method section' of medical research articles

\begin{tabular}{|c|c|c|c|c|}
\hline \multirow[b]{2}{*}{ Sub-types } & & \multicolumn{3}{|c|}{ The Binary Comparisons } \\
\hline & & Native & Native & Iran ISI \\
\hline of & & / Iran ISI & / Iran Non- ISI & / Iran Non- ISI \\
\hline \multicolumn{5}{|l|}{ Interactional } \\
\hline \multicolumn{5}{|l|}{ Markers } \\
\hline \multirow[t]{4}{*}{ Self -mentions } & Value & 11.7 & 30.47 & 5.88 \\
\hline & of & & & \\
\hline & Chi- Square & & & \\
\hline & Number & 73.73 & 60.25 & 30.88 \\
\hline Engagement- & Value & - & - & - \\
\hline \multirow[t]{3}{*}{ Markers } & Of & & & \\
\hline & Chi- Square & & & \\
\hline & Number & - & - & - \\
\hline \multirow[t]{4}{*}{ Attitude Markers } & Value & 0.00 & 1.53 & 1.42 \\
\hline & of & & & \\
\hline & Chi- Square & & & \\
\hline & Number & 7.53 & 4.92 & 4.78 \\
\hline \multirow[t]{4}{*}{ Boosters } & Value & 4.73 & 0.57 & 2.04 \\
\hline & of & & & \\
\hline & Chi- Square & & & \\
\hline & Number & 153.01 & 134.84 & 161.74 \\
\hline \multirow[t]{6}{*}{ Hedges } & Value & 0.00 & 0.17 & 0.17 \\
\hline & Of & & & \\
\hline & Chi- Square & & & \\
\hline & Number & 45.59 & 42.91 & 42.92 \\
\hline & DF & 1 & 1 & 1 \\
\hline & $\mathrm{P}$ & 0.05 & 0.05 & 0.05 \\
\hline
\end{tabular}

Table 3.5 demonstrated that there were significant differences between the Native and the Iran ISI as well as Iran nonISI groups individually as for employing self-mentions. The findings of Table 3.5 also revealed that there was a significant difference between the Native and the Iran ISI group for using boosters.

\section{Discussion}

The outcomes of the study indicate that the study groups vary in terms of the number of employing interactional markers. These variations could be justified by what Mauranen (1993a, 1993b) and Vaero-Garces (1996) state, that is, the influence of cultural backgrounds of writers. On the other hand, the ranked order of using interactional markers is identical within the groups. It seems that, they, to a great degree, follow the same disciplinary culture and write within a unique framework identified by the genre -the 'method section' genre of medical research article genre- even though they may be influenced by different linguistic (L1and L2 Interlanguage), cultural, educational, and social backgrounds . Furthermore, the effect of overgeneralization and interference between English and Persian can be taken into consideration.

The Findings concerning employing self- mentions by Iranian ISI and Iranian non- ISI writers suggest that they have underused certain self- mentions in 'method section' of their respective articles.

Employing personal pronouns by the native writers indicate that they do not detach themselves from the discourse community and it allows them to get involved in the argument (Hyland, 2001a). 'We' as a self- mention have been underused by the Iran ISI and the Iran non- ISI groups as compared with the Native group. Self- mention as a rhetoric tool helps the writer to claim an appropriate degree of authoritativeness as well as to admit personally the responsibility of the words in the text (Hyland, 2001a). The dominance of ' $w e^{\prime}$ over 'I' tends to suggest that authors employ 'we' to diffuse responsibility by making it seem more collective (Ekok, 2011; Koutsantoni, 2006).On the other hand, ' $I$ ' constitutes a larger portion of the articles written by the Iranian groups as compared to the Native one. Therefore, as Wishnoff (2000) argues, culture is significant in defining what we say, and how, where, and when we say it. 
Ivanic (1998) points out using ' $I$ ' is critical to credibility of the text, and helps to establish the commitment of writers to their words and setting up a relationship with their readers. During a study on expert writers, Hyland found that academics made extensive use of exclusive first person pronouns to strengthen their arguments and gain personal recognition for their claims, but the elegant point is latent in how writers perceive self -reference and in what the writers' explanations are for the communicative practice (Hyland, 2001a). Therefore, according to him it seems that, self- mention is related with rhetorical identity, though the notion of identity is relatively new in writing research. The notion of identity in this paradigm is viewed as being located within the discourse community, and is understood in terms of a social view in language and not as the manifestation of an individualistic self-rooted in private experience since he (Hyland, 2001a) points out that to Shotter and Gergen (1989) identity is less a phenomenon of private experience than a desire for affiliation and recognition in particular social networks. Employing the discourses of a community requires taking on the identity of a member of that community to represent ourselves in a way valued by it. Ivanic argues that' some of our students may have already written a lot in their first language, but even if they have, writing in English involves them portraying themselves differently. On the other hand, Doyle (2005) maintains that students need to get used to portraying themselves and their identities in English and in a context which is probably quite foreign to them and may be even threatening. Furthermore, as Hyland (2002) states authorship in English academic writing both carries a culturally constructed individualistic ideology and places the burden of responsibility for the truth of an assertion heavily on the shoulders of the writer. He adds that, but the texts and interviews show that this notion of a rational, uniquely individual writer is a product of a culturally specific ideology. While the students are sensitive to the effects of author pronouns, they may be reluctant to accept its clear connotations of authority and commitment (Hyland, 2002). With regard to the notions mentioned above, though it seems that the writers of the nonnative study groups belong to a expert community and of relatively good proficiency in English, it is likely that, the two Iranian groups are involved in some vernacular cultural ideological issues that inhibit them from expressing themselves in a more authoritative way and simultaneously taking on more accountability to the readers.

According to Cadman (1997), the other problem lies in the gap between epistemological orientations of different cultures as students are unclear about "who they are expected to be" and are unable to establish their own position in their writing and the absence of clear direction in their pedagogic texts exacerbate these difficulties.

The other issue is that in science writers downplay their personal role to highlight the phenomena under study. Such a strategy subtly conveys an empiricist ideology that suggests research outcomes would be the same irrespective of the individual conducting it (Hyland, 2002; Hyland, 2005b). It is imperative that Iranian non- ISI groups should be more taken into consideration than the Iranian ISI group since in the opinion of the researcher, it seems that the reason for achieving higher norm of employing self- mentions by the Iran ISI group as compared with the Iran non- ISI, is that the former has had unconsciously more self- confidence concerning their conducted research. It is necessary to mention that in the most competitive fields, authors are trying to find new ways to promote themselves as many have started to use "we" more frequently.

It seems to the writer of these lines, it is likely as one of the ways of the justification that the people of a country that governed by dictatorship or by colonialism, presumably cannot give the sense of identity to their people specially, a plural one. The shortage of establishing democracy and lack of freedom and respect can result in anticipating what are in others' hands for everything that is not ours. It is likely that, unconsciously we are affected by historical and cultural heritages-good or bad- that influence our behavior, for instance writing research articles. The idea of democracy is, after all, closely intertwined with ideal of making transparent decisions based on high quality open discussions in public domain (Haaften et al, 2011) that can be manifested particularly in employing appropriate amount of self-mentions, and hedges.

Engagement markers are the ways writers bring readers into the discourse to anticipate their possible objections and engage them in appropriate ways. It seems that, due to the special characteristic of 'method section', employed engagement markers comprise a small portion of interactional markers in 'method section' of medical RAs.

The results confirm that 'see' is the only employed engagement marker by the Native group. None of the groups has used 'You' and 'Your' in their respective articles since 'You' and 'Your' are actually the clearest way that a writer can acknowledge the reader's presence, but these forms are rarely used outside of philosophy, probably because they imply a lack of involvement between participants. Engagement markers explicitly address readers to selectively focus their attention or to include them in the text. Instead, there is enormous emphasis on binding writer and reader together through inclusive 'we', which is the most frequent engagement device in academic writing. But, 'we' were not employed by the groups in medical articles as an academic article because the nature of 'method section' does not require using 'we' (Hyland, 2005b). In contrast to 'we', the occurrence of 'you' in academic writing is very rare (Kuo, 1999). Furthermore, while science research articles make extensive use of imperatives for this purpose, they almost never include other forms, such as second-person pronouns, questions and asides (Hyland, 2001b). Analysis of the present corpus of study shows that the expression of engagement is not intensely an important feature of academic writing of 'method section' in medical research articles (The Native, the Iran ISI and the Iran non- ISI groups have employed 3.41, 0 and 0 instances of engagement markers per 10,000 words, respectively). This issue may be better explained by Hyland's study (2005b), that medicine as a hard science employs less engagement markers as compared with the more discursive soft fields as philosophy. Generally speaking, the justification for these findings is that different disciplines represent themselves in different ways, that is, different resources of language mediate different contexts and the characteristic structures of knowledge domains and also the argumentative forms of the disciplines.

Soft knowledge domains are more interpretative and less abstract (Hyland, 2005b), thus writers need to spell out their evaluations and work harder to establish an understanding with readers. Furthermore, they are far less able to rely on general understandings and on the acceptance of proven quantitative methods to establish their claims and these issues 
increase the need for more explicit evaluation and engagement. Articles in hard sciences also tend to be much shorter, probably due to editorial efforts to facilitate the rapid growth of knowledge and high submission rates.

It should also be noted that this creation of an authorial persona through engagement markers as Hyland maintains (2005b) is an influence of individual personality, confidence, experience, and ideological preference, therefore even the most rhetorically innocent sections reveal writers' efforts to persuade their audience of their claims across research papers.

As for employing Attitude Markers the findings confirm that none of the study groups including the Iranian ISI and non- ISI groups has trouble with using attitude markers as compared with the Native group.

The results indicate that more or less the same linguistic forms are used for expressing authors' attitudes in the articles, but the range of employed attitude markers are restricted to a few items . Using a limited number of attitude markers could result from specificity of 'method section' genre that it deals with reporting material and procedures related to researches, therefore, it requires the writers to indicate less presence of the writer's attitude (persuasion and affection) in expressing the procedural aspects of the text since it is to be mostly objective and to be replicable by the experts of the discourse community.

As the findings of the present study demonstrate, boosters constitute the most frequent markers within interactional category in 'method section' of medical RAs followed by self- mentions (63.05 instances per 10000 words) within the native group. On the other hand, boosters are more frequent than hedges in the native corpus, and according to Hyland (2005) the predominance of hedges over boosters in the corpus is partially a consequence of this need to soften the announcement of poor results and account for setbacks, thus boosters allow writers to project a credible image of authority, decisiveness and conviction while hedges demonstrate personal honesty and integrity through a willingness to address hard realities, albeit behind a shield of mitigation. Therefore, it seems that due to factual nature of 'method section' genre and requirement for elaborating and illuminating the text to provide assurance for replicating the results, boosters are more common than hedges.

The Findings concerning employing boosters demonstrate that the Iran ISI and the Iran non- ISI groups both have employed an excessive amount of boosters within 'method section' of their respective articles, though finally Iran non ISI group has achieved in employing boosters and the Iran ISI group has not succeed in the importance. It is also illuminated that Iran ISI group has employed verb forms (75.18 per 10, 000 words), adjectival forms (6.78 per 10,000 words), and adverbial forms ( 8 per 10.000 words).

Boosters not only take the form of verbs (87.15\%) but are adjectival (4.73\%) or adverbial $(8.12 \%)$ forms within the Native group. Iranian ISI writers used an excessive amount of verbal boosters. Overusing boosters by the Iran ISI may partly be accounted for by the discoursal choices of the researchers deciding to represent themselves more or less explicitly in their writing. These choices are to some extent influenced by individual personality factors, such as selfconfidence and experience, and they are often regarded as largely unreflective and automatic aspects of writing (Hyland, 1998b). Overusing boosters by Iranian ISI writers perhaps could be explained by the idea of, 'displaying expertise' that is also observable in Kennedy and Thorp's (2007) study. Kennedy and Thorp argue that "the expert L2 writers are displaying their expertise and facility in the language more overtly than we imagine an L1 writer would in a similar context."

The difference between Iranian writers in utilizing boosters might result from their insufficient awareness of the role of interactional markers and the fact that they do not usually receive explicit instruction concerning these rhetoric devices. The existence of some ambiguity from the view point of multiplicity of pragmatic meanings that the markers convey as well as the extensive range of metadiscourse markers in English may create trouble for non- native researchers of the articles. Overusing certain items by the Iran ISI group may be representative of a Persian stylistic feature or perhaps the group has a restricted repertoire of boosters. Academic English is characterized by use of more hedges and less boosters, which indicates that English writers are more tactful in asserting their claims and they tend to address their readers indirectly, but Iranian writers seem to be less conservative and instead address their readers directly. The danger in overusing boosters is that they put the writer at the risk of being criticized by the readers. Overusing boosters by Iranian writers might demonstrate that they are so sure of their results that they use forceful expressions, leaving little doubt that their interpretation must be otherwise and this issue might imply Iranian writers' fragile knowledge of such devices.

As findings verify both Iran ISI and Iran non- ISI groups are needless of any instruction because they have achieved in writing 'method section' of medical research articles as the native writers for employing hedges. The results show that 'may' (13.08\% )and 'overall'(13.08\%) are the most widely used ones. 'May' is also of more frequency than 'might'(2, $80 \%$ ) in the Native group. The Iran ISI and the Iran non- ISI groups have not employed ' might'. The Iran ISI group has not employed 'overall'. However', the Iran non- ISI group has employed 'overall'( $8.11 \%)$. Moreover, the Iran ISI group has overused,' randomly', 'nearly'(16.22\%), 'mainly' (16.22\%) and has underused' can', 'could be', and 'may have'. The Iran non- ISI group has overused 'about',' nearly' (5.41\%), 'Would be', 'should', 'appear' and has underused 'randomly', 'can be', 'can', 'may' (10.81\%). Modal verbs and attribute hedges constitute $51.39 \%$ and $44.87 \%$ of the total employed hedges in the Native group. Modal verbs include 'may', 'might', 'would be', 'could be', 'could not be', 'may have', 'can be', 'can', and 'should'. Attribute hedges consist of 'about', 'approximately', 'randomly', 'nearly', 'almost', 'apparently', 'around', 'overall', 'likely', 'generally', and 'mainly' that they refer to the relationship between propositional elements rather than the relationship between a proposition and a writer and limit the scope of the accompanying statement, rather than cast doubt on its certainty (Hyland, 1998b) and draw on shared standards of permissible imprecision (Channel, 1990; Dubois, 1987). Modal verbs are less specific in attributing a source to a viewpoint and tend to downplay the person making the evaluation- a preference for impersonal strategies in the hard sciences as medicine 
(Hyland, 1998b). 'May' occurred over four times more than 'might'. 'May' is the only modal to figure notably more often in academic genres, perhaps because of its perceived formality and 'might' is a more tentative form than 'may', perhaps because the condition of realization is more remote (Hyland, 1996a). Examining the results reveal that, 'would', 'could', 'could not', and' can' followed by 'be' within the corpus including 'would be', 'could be', 'could not be', and 'can be', syntactically. Moreover, 'appear' was employed as the only lexical verb within the corpus which are representative of impersonalization strategies such as the use of passives, nominalization, and objective theme selections that have been well-documented in the literature and appear to represent the rhetorical face of science (e.g. Gosden, 1993; Swales, 1990). This effect is often reinforced by use of an embedded clause with an anticipatory or dummy 'it' replacing a human agent as subject and by discourse-oriented verbs as 'appear' instead of 'think', and 'believe' that are more easily combined with inanimate subjects. This allows writers to more easily attribute agency to 'abstract rhetor', a common practice in science. In other words, they contribute to the ideological representation that scientists discover truth rather than construct it, minimizing the role of socially contingent factors in scientific research practices (Hyland, 1998b). 'Would' and 'should' are the principal markers of hypothesizing. 'Would' is also used pragmatically, where it appears to attenuate a proposition unnecessarily and express caution rather than a genuine hypothesis. 'Should' typically refers to the future and consequently has a more tentative meaning than 'would', expressing a less confident assumption of probability based on known facts (Hyland, 1996b). 'Will' is the main difference between the general academic corpora and the science material, for instance medicine as a hard science and according to Hyland (1996b) this may be explained by the fact -its hedging sense-, to make predictions based on anticipated outcomes, that is perhaps more suited to less cautious fields than the hard sciences. Making use of ' will' and 'must' in scientific writing usually refers to general truths, the justification for the assurance being based on repeated experience rather than logical inference. Hyland argues that (1996b) science writers often prefer 'would' to 'will' in discussing present time probabilities. However, this is more conditional and can be used to express hypothetical predictions or tentative deductions and indicate less confidence in outcomes. It is therefore more appropriate in a forum where speculation and tentativeness is crucial. Hyland adds that as Collins (1991) states, 'must' is the predominant modal of inferential confidence in spoken discourse although its relative infrequency in scientific discourse again suggests that writers are reluctant to express even weak convictions when making deductions. It is often replaced in the journal corpus by epistemic 'could' which expresses tentative possibility. This is because of the speculative nature of scientific research compared with the greater proportion of digest and textbook material in the general academic corpora. On the whole, hedges comprise $3.98 \%$ of total metadiscourse markers employed within 'method section' of articles written by the Native group in the present study. The reasons for restricted use of hedges in 'method section' genre are that hedges are differently distributed across different parts of each genre, with their use especially marked in more discursive sections. They are particularly prevalent in introduction and discussion sections of research articles and the comment section of clinical case notes (Adams Smith, 1984; Salager-Meyer, 1994). It is here that writers are seeking to establish relevance and significance of their research and plausibility of their interpretations. Therefore; it is where they need to be more tentative and circumspect in their assertions. There is also evidence that the type of hedges employed differ as well, with contentoriented hedges dominating methods and results sections and more reader-oriented forms being found in introductions and discussions (Hyland, 2006a; Salager- Mayer, 1994). These patterns allow writers to convey approximations when discussing symptoms and methods and to evaluate, interpret, and comment on the evidential status of their information in the discursive sections.

\section{Conclusion}

As an overall picture of the present research, the Iran ISI and Iran non- ISI groups show an overusing of boosters and underusing self- mentions. They have succeeded in employing an appropriate number and types of hedges. Writing in a second language is complicated by first language literacy, differences in culture, and rhetorical approaches to the text. It is also influenced by issues of proficiency in the target language, thus the findings of the study may be utilized for planning instruction in writing to improve students' and experts' proficiency in a key area as metadiscourse markers.

\subsection{Suggestions for Further Research}

Some relevant areas for further research based on the findings of this study are suggested as follows:

There could be other studies in the future examining introduction, results, and discussion sections of medical articles with respect to metadiscourse analysis to portray a more comprehensive description of Iranian and non- Iranian medical RAs.

Metadiscourse features in ISI and non-ISI Iranian journals written particularly, in English can be contrasted with those of native ones to find out the related linguistic and cultural differences.

The pedagogical explicit activities by emphasis on findings of the rhetorical researches can be followed by experimental studies to observe their respective feedback.

The metadiscourse features used within scientific discourse as medicine can be contrasted with those used in Persian ones to demonstrate to draw on the results for pedagogical purposes.

\section{References}

Ädel, A., \& Mauranen, A. (2010). Metadiscourse: Diverse and divided perspectives. Nordic Journal of English

Studies, 9 (2), 1-11.

Adams Smith, D.E. (1984). Medical discourse: Aspects of author's comment. English for Specific Purposes, 3 , 25-36. 
Barton, E., \& Stygall, G. (2002). Discourse studies in composition. Cresskill, NJ: Hampton Press.

Beauvais, P. (1989). A speech act theory of metadiscourse. Written Communication, 6 (1), 11-31.

Berkenkotter, C., \& Huckin, T. N. (1995). Genre knowledge in disciplinary communication: Cognition/Culture/ Power. Hillsdale, NJ: Lawrence Erlbaum.

Bondi, M. (2005). Metadiscursive practices in academic discourse: Variation across genres and disciplines. In J.

Bamford and M. Bondi (Eds.), Dialogue within discourse communities: Metadiscourse perspectives on academic genres, (pp. 3-30). Tübingen: Niemeyer.

Brett, P. (1994). A genre analysis of the results section of sociology articles. English for Specific Purposes, 13 (1), $47-$ 59.

Cadman, K. (1997). Thesis writing for international students: a question of identity? English for specific

Purposes, 16 (1), 3-14.

Camiciottoli, B.C. (2003). Metadiscourse and ESP reading comprehension: An exploratory study. Reading in a Foreign Language, 15(1), 1-16.

Cavalieri, S. (2011).Exploring Courtroom Discourse: The Language of Power and Control. In A. Wagner \& L. Cheng (Eds.), The role of metadiscourse in council's questions (pp.79-111).Ashgate Publishing Company: USA.

Channel, J. (1990). Precise and vague quantities on writing in economics. In W. Nash (Ed.), The writing scholar: Studies in academic discourse. Newbury Park, CA: Sage.

Cheng, X., \& Steffensen, M. (1996). Metadiscourse: A technique for improving student writing. Research in teaching of English, 30 (2), 149-181.

Coe, R.M., Lingard, L. \& Teslenko, T. (2002). The rhetoric and ideology of genre: Strategies for stability and change, Cresskill, NJ: Hampton Press.

Connor, U.M. (2002). New directions in contrastive rhetoric. TESOL Quarterly, 36 (4), 493-510.

Connor, U.M. (2004). Contrastive rhetoric: Old and new directions. In N. Kassabgy., Z. Ibrahim., \& S. Aydelott (Eds.), Contrastive rhetoric: Issues, insights and pedagogy (pp. 1-25). Cairo, Egypt: The American University in Cairo Press.

Crismore, A. (1989). Talking with Readers: Metadiscourse as Rhetorical Act. New York: Peter Lang Publishers.

Crismore, A. (1984). The rhetoric of textbooks: Metadiscourse. Journal of Curriculum Studies, 16 (3), 279-96.

Crismore, A., \& Abdollehzadeh, E. (2010). A review of recent metadiscourse studies: The Iranian context. Nordic

Journal of English Studies, 9(2), 195-219.

Crismore, A., Markkanen R., \& Steffensen, M.S. (1993). Metadiscourse in persuasive writing: A study of texts

written by American and Finnish university students. Written Communication, 10 (1), 39-71.

Dafouz-Milne, E. (2003). Metadiscourse revisited: A contrastive study of persuasive writing in professional discourse. Estudios Ingleses de la Universidad Complutense, 11, 29-52.

Dalton-Puffer, C., Nikula, T., \&, Smit, U. (Eds.). (2010). Language use and language learning in content and language integrated learning (CLIL) classrooms. Amsterdam: John Benjamins Publishing Company.

Doyle, T. M. (2005). Writing and identity in adult/non-credit beginning level classes. Proceedings of the CATESOL state conference. Grace Song.

Dubois, B.L. (1987). Something in the order of around forty to forty four: Imprecise numerical expressions in biomedical slide talks. Language and Society, 16, 527-541.

Eggins, S. (1994). An introduction to systemic functional linguistics. London: Pinter.

Ekoc, A. (2011). Analyzing Turkish MA students' use of lexical hedging strategies in theses abstracts. Hasan Ali Yücel Eğitim Fakültesi Dergisi, 13, 49-62.

Mao, L. (1996). Encyclopedia of rhetoric and composition: Communication from ancient times to the information Age. In T. Enos (Ed.), Metadiscourse (pp.437-438). New York: Garland.

Gosden, H. (1993). Discourse functions of subject in scientific research articles. Applied Linguistics, 14 (1), 57-75.

Haaften, T. V., Jansen, H., De Jong, J. \& Koetsenruijter, W. (2011). Bending opinion: Essays on persuasion on public domain-rhetoric in society. Amsterdam: Leiden University Press.

Hashemi, M.R. et al. (2012). The effect of metadiscourse on EFL learners' listening comprehension. Journal of Language Teaching and Research, 3(3), 452-458.

Honeycutt, L. (2000). Aristotle's rhetoric. http://www2.iastate.edu/ honeyl/Rhetoric/rhet1-2.html/(accessed 12/6/2012)

Hopkins, A., \& Dudley-Evans, T. (1988). A genre-based investigation of the discussion sections in articles and dissertations. English for Specific Purposes, 7 (2), 113-121.

Hyland, K. (1996a). Writing without conviction? Hedging in science research articles. Applied Linguistics, 17 (4). $433-$ 454.

Hyland, K. (1996b). Talking to the academy: Forms of hedging in science research articles. Written Communication, 13 (2), 251-281.

Hyland, K. (1998a). Boosting, hedging and the negotiation of academic knowledge. Text, 18 (3), 349-382.

Hyland, K. (1998b). Hedging in scientific research articles. Amsterdam: Benjamins.

Hyland, K. (1999a). Academic attribution: Citation and the construction of disciplinary knowledge. Applied Linguistics, 20 (3), 341-367. 
Hyland, K. (1999b). Talking to students: Metadiscourse in introductory coursebooks. English for Specific Purposes, $18(1), 3-26$.

Hyland, K. (2000). Disciplinary Discourses: Social Interactions in Academic Writing. Harlow: Pearson Education.

Hyland, K. (2001a). Humble servants of the discipline? Self-mention in research articles. English for Specific Purposes, 20 (3), 207-226.

Hyland, K. (2001b). Bringing in the reader: Addressee features in academic articles. Written Communication, 18(4), 549-74.

Hyland, K. (2002). Authority and invisibility: Authorial identity in academic writing. Journal of Pragmatics, 34 (8), 1091-1112.

Hyland, K. (2004b).Disciplinary interactions: Metadiscourse in L2 postgraduate writing. Journal of Second Language Writing, 13 (2), 133-151.

Hyland, K. (2005). Metadiscourse: Exploring Interaction in Writing. London: Continuum.

Hyland, K. (2006a). Medical discourse: Hedges. London: Elsevier Ltd.

Hyland, K. (2006b). English for academic purposes: An advanced resource book. London \&New York: Routledge: Taylor and Francis Group.

Hyland, K. (2007). Applying a gloss: Exemplifying and reformulating in academic discourse. Applied Linguistics, 28 (2), 266-285.

Hyland, K. (2010). Metadiscourse: Mapping Interactions in Academic Writing. Nordic Journal of English Studies, 9 (2), 125-143.

Hyland, K., \& Tse, P. (2004). Metadiscourse in academic writing: A reappraisal. Applied Linguistics, 25 (2), 156-177.

Hyon, S. (1996). Genre in three traditions: Implications for ESL. TESOL Quarterly, 30 (4), 693-722.

Ivanic, R. (1998). Writing and identity: The discoursal construction of identity in academic writing. Amsterdam: Benjamins.

Jalilifar, A., \& Alipour, M. (2007). How explicit instruction makes a difference: Metadiscourse markers and EFL learners' reading comprehension skill. Journal of College Reading and Learning, 38 (1), 35-52.

Kanoksilapatham, B. (2005). Rhetorical structure of biochemistry research articles. English for Specific Purposes, 24 (3), 269-292.

Kaplan, R.B. (1966). Cultural thought patterns in inter-cultural education. Language Learning, 16 (1), 1-20.

Kennedy, C., Thorp, D. (2007). A corpus-based investigation of linguistic responses to an IELTS academic writing task. In L. Taylor \& P. Falvey (Eds.), Studies in language testing 19 IELTS collected papers. Research in speaking and writing assessment (pp. 316-377). Cambridge: Cambridge University Press.

Koutsantoni, D. (2006). Rhetorical strategies in engineering research articles and research theses: Advanced academic literacy and relations of power. Journal of English for Academic Purposes, 5 (1), 19-36.

Kuo, C.H. (1999).The use of personal pronouns: Role relationships in scientific journal articles. English for Specific Purposes, 18(2), 121-138.

Kwan, B. S.C. (2005). The schematic structure of literature reviews in doctoral theses of applied linguistics. English for Specific Purposes, 25(1), 30-55.

Lewin, B., Fine, J., \& Young, L. (2001). Expository discourse: A genre based approach to social science texts. London: Routledge.

Livnat, Z. (2012). Dialogue, science, and academic writing. Amsterdam; Philadelphia: John Benjamins Publishing Company.

Mauranen, A. (1993a). Contrastive ESP rhetoric: Metatext in Finnish-English economic texts. English for Specific Purposes, 12, 3-22.

Mauranen, A. (1993b). Cultural differences in academic rhetoric. Frankfurt am Main: Peter Lang.

Myers, G. (1989). The pragmatics of politeness in scientific articles. Applied Linguistics, 10 (1), 1-35.

Nwogu, N. K. (1997).The medical research paper: structure and functions. English for Specific Purposes, 16 (2), $119-$ 138.

Parvaresh, V., \& Nemati, M. (2008). Metadiscourse and reading comprehension: The effects of language and proficiency. Electronic Journal of Foreign Language Teaching, 5(2), 220-239.

Peacock, M. (2002). Communicative moves in the discussion section of research articles. System.30, 479-497.

Perez, M.A., Macia, I. A. (2002). Metadiscourse in lecture comprehension: Does it really help foreign language learners? Allantis, 14(2), 3-21.

Salager-Meyer, F. (1994).Hedges and textual communicative function in medical English written discourse. English for Specific Purposes, 13 (2), 149-170.

Samraj, B. (2002a). Introductions in research articles: Variation across disciplines. English for Specific Purposes, 21 (1): $1-17$.

Samraj, B. (2002b). Texts and contextual layers: academic writing in content courses. In A.M. Johns (ed.), Genre in the Classroom: Multiple Perspectives. (pp. 163-176). Mahwah: Lawrence Erlbaum.

Soler, V. (2007). Writing titles in science: An exploratory study. English for Specific Purposes, 26 (1), 90-102.

Swales, J. M. (1981). Aspects of article introductions. Birmingham, UK: Aston University. 
Swales, J.M. (1990). Genre Analysis: English in academic and research settings. Cambridge: Cambridge University Press.

Swales, J. M. (2004). Research genres: Explorations and application. Cambridge: Cambridge University Press.

Swales, J.M. (2010). From context to text: Investigating structures, functions, and forms in today's research article. http: // www.lattice.cnrs.fr/ (accessed 12/6/2012).

Swales, J. M., Chang, Y., Chavez, D., Dressen, D., \& Seymour, R. (1998). Consider this: The Role of Imperatives in Scholarly Writing. Applied Linguistics, 19 (1), 97-121.

Thompson, S. (1994). Frameworks and contexts: A genre-based approach to analyzing lecture introductions. English for Specific Purposes, 13 (2), 171-186.

Thompson, G. (2001).Interaction in academic writing: Learning to argue with the reader. Applied Linguistics, 22 (1), 58-78.

Thompson, P. (2000). "Citation practices in PhD theses. In rethinking language pedagogy from a corpus perspective. In L. Burnard \& T. McEnery (Eds.), Papers from the 3rd International Conference on Teaching and language corpora (pp. 91-101). New York, NY: Peter Lang.

Vande Kopple, W.J. (1985). Some exploratory discourse in metadiscourse. College Composition and Communication, 36, 82-93.

Vande Kopple, W.J. (2002). Metadiscourse, discourse, and issues in composition and rhetoric. In E. Barton \& G. Stygall (Eds.), Discourse studies in composition (pp. 91-114). Gresskill, NJ: Hampton Press, Inc.

Valero-Garcés, C. (1996).Contrastive ESP rhetoric: Metatext in Spanish-English economics texts. English for Specific Purposes, 15(4), 279-294.

Vázquez, I., Giner, D. (2009).Writing with conviction: The use of boosters in modeling persuasion in academic discourses. Revista Alicantina de Estudios Ingleses, 22, 219-237.

Williams, J.M. (1981). Style: Ten lessons in clarity and grace. New York: Harper Collins Publishers.

Wishnoff, L. A. (2000). Hedging your bets: L2 learners' acquisition of pragmatic devices in academic writing and computer-mediated discourse. Second Language Studies, 19 (1), 119-148.

\section{Appendix 1}

List of 91 potentially productive searched metadiscourse items targeted for metadiscourse analysis of 'method section' in medical research articles of the present study

\begin{tabular}{|c|c|c|}
\hline \multirow{5}{*}{ 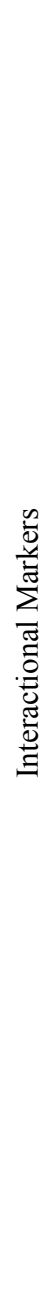 } & 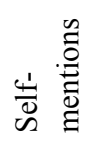 & I- Me- My- We- Us- Our- This writer- The research team- Mine- Ours \\
\hline & 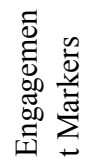 & Consider- See- Note that- Notice- You can see that- By the way- Choose- Look at \\
\hline & 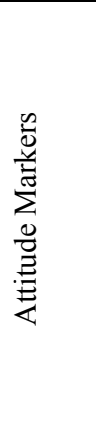 & $\begin{array}{l}\text { Unfortunately- Surprisingly- I agree- It is interesting that- Overwhelmingly- Paradoxically- } \\
\text { Pragmatically- Oddly enough- Most strikingly- Quite simply- More importantly- More important- } \\
\text { Most important- Most importantly- Significantly- tellingly- It is difficult-It is remarkable-It is } \\
\text { essential- It would be naïve- ample- Modest- More unobtrusive- Less attractive- Problematic- } \\
\text { Simplistic- Too simplistic- Too often- Honestly significant- Should be- Must be- The paradox- } \\
\text { Danger- It is tempting to credit- perceptive- it is necessary- it is crucial- it is important- I disagree- } \\
\text { like- logical- appropriate- misguided- hopefully- Fortunately- Outstanding- Honestly- Personally- } \\
\text { Candidly- Naturally- Even more- Importantly- On the contrary- In all honesty- To be precise- To be } \\
\text { sure- I find it interesting that- It is alarming to note that- I hope- With little justification- Ideally- } \\
\text { Ironically }\end{array}$ \\
\hline & $\begin{array}{l}n \\
\stackrel{0}{0} \\
\dot{0} \\
\infty \\
\infty\end{array}$ & $\begin{array}{l}\text { Sequential- It is clear that- In fact- Definitely- Clearly- Are shown- Found- Dominantly-Observed- } \\
\text { Determined- Carefully- Significant- Completely- Represented- Presented- yielded- Confirmed- } \\
\text { Approved- Assigned- Supported- Indicated- Recorded- Verified- Repeatedly- Apparently- Evidently- } \\
\text { Discovered- Detected- Exhibited- Proved-Thought- Demonstrate- Showed- Firmly -Believe- Beyond } \\
\text { doubt- No doubt- Conclusively- Actually- Always- Sure- Signifies- Exemplify- Display- } \\
\text { Undoubtedly- Only- Prompted- Defined- Planned- Supplied- Managed- Occurred- Made- Used- } \\
\text { Designated- Processed- Resulted in- Operated- Assayed- Analyzed- Expressed }\end{array}$ \\
\hline & 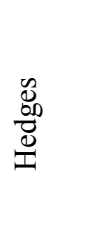 & $\begin{array}{l}\text { Might- About- Perhaps- Possibly- Approximately- Would be- Could not be- Could be- Randomly- } \\
\text { Shortly- Nearly- It should be- Some of the time- Can be- Almost- Can- Probably- Apparently-Appear- } \\
\text { Around- Presumably- Supposedly- It would appear that- Sort of- Quite rather- Overall- Likely- } \\
\text { Generally- in general- More or less- Argued- Suggesting that- Kind of- Basically- Effectively- } \\
\text { Evidently- Fairly- Mainly- May- May be- Mostly- Pretty- Quite clearly- Really quite- Seem- } \\
\text { Somewhat- Feel- Should- There is a good reason to believe that- May be possible }\end{array}$ \\
\hline
\end{tabular}

